\section{Energy Demand and Climate Change: Issues and Resolutions}

by Franklin Hadley Cocks: Wiley-VCH, Weinheim, Germany, 2009, pp 251, ISBN: 978-3-527-32446-0.

Price: EUR 24.90, GBP 37.50

It is very regrettable that the concept of global warming has been forced to move from a scientific platform into the hotbed of political controversy. That modern societies are enormously wasteful of the Earth's resources is beyond doubt, but by targeting the global warming theory as their primary weapon politicians are hitting many wrong targets in their attempts to react to a probable but as yet unproven theory, all at great cost to the societies they are meant to represent. In staying well away from political issues, the author lets science, technology, engineering and imagination do his talking. To his credit strict neutrality is retained throughout, although the principle of global warming is accepted based upon his (sound) scientific analysis. By eliminating jargon and keeping the presentation simple this is an eminently readable text, covering most levels of potential readership.
The book is divided into four sections: Part 1 deals with the human use of energy; Part 2 reviews current technology; Part 3 assesses possible future technology; and Part 4 takes an apocalyptic view if all else fails. In principle the heat balance of the Earth is simple. Energy loss is entirely in the form of emitted infrared radiation of which about $30 \%$ is reflected back by clouds. What, then, disturbs this equilibrium? The Sun, Earth's orbit, planetary angles, clouds, dust, water vapour, methane, $\mathrm{CO}_{2}$ ? Each is discussed in detail. Water vapour is in fact the major greenhouse gas. It has been calculated if the ocean temperature increases by $3{ }^{\circ} \mathrm{C}$ then evaporation increases by $20 \%$, an effect largely ignored by most doomsayers whilst they concentrate on $\mathrm{CO}_{2}$.

The physics used to exemplify the various facets are simplified by using comparative energy sources related to the scale of human endeavour, and by citing at every opportunity the name of the (often long-dead) scientists associated with particular discoveries adds considerably to the interest. The subject matter is cleverly structured, moving easily between sections that on first sight are not meaningfully related. An unusual and most important feature is that wherever possible the relative economic impact of the individual technology is considered. This factor appears to be largely missing when political decisions are made. Huge subsidies are inevitably required for alternative technologies, specifically renewables, but these are kept very well hidden from public scrutiny, a technique that will eventually undermine the political stance.

Of interest to many will be the imaginative solutions offered to create energy without emitting $\mathrm{CO}_{2}$. There is any number of options, but the warning is clear, capital cost will be huge. Nevertheless there are viable solutions, and all are examined in some detail, ranging from the mundane to the exotic. The section on potential nuclear generation is fascinating. Just one statistic: $1 \mathrm{~kg}$ of uranium produces 3 million times more energy than $1 \mathrm{~kg}$ of coal; and $1 \mathrm{~kg}$ of tritium (when fusion becomes possible) will produce 30 times more than $1 \mathrm{~kg}$ of uranium - all without $\mathrm{CO}_{2}$ emission.

Most readers would probably agree that if only politicians could be made to read this book they then would be convinced that much of the current taxation and subsidy policy should be consigned to the dustbin and replaced by at least one of the other carbon-free technologies so elegantly described here. 